\title{
Los avatares de la mancomunión. Propiedad indivisa, armonías y conflictos en las costas del río Dulce. Santiago del Estero, siglos XVIII y XIX
}

por

Judith Farberman ${ }^{1}$

CONICET/Universidad Nacional de Quilmes

En Santiago del Estero, noroeste de Argentina, se denominaba «mancomún» a las propiedades indivisas gestionadas colectivamente. Este tipo de estructura agraria tuvo relativa difusión durante la colonia y el siglo XIX y puede relevarse tanto en grandes estancias como en propiedades campesinas.

En este articulo se profundizan tres cuestiones a partir de ejemplos coloniales de la zona del rio Dulce: la racionalidad, la membresía y las jerarquías de los campos comunes.

Palabras Clave: Derechos de propiedad; mancomún; Santiago del Estero; colonia; propiedad indivisa.

Cómo CitAR ESTE ARTí́culo / CitATION: Farberman, Judith, «Los avatares de la mancomunión. Propiedad indivisa, armonías y conflictos en las costas del río Dulce. Santiago del Estero, siglos XVIII y XIX», Revista de Indias, LXXIX/275 (Madrid, 2019): 111-142. https:// doi.org/10.3989/revindias.2019.004.

\section{INTRODUCCIÓN}

Este trabajo se ocupa de una forma específica de la propiedad indivisa, en una región de antigua colonización del norte argentino situada en la actual provincia de Santiago del Estero. «Poseer en mancomún» fue el término que los actores coloniales y del siglo XIX utilizaron con mayor frecuencia para designar un modo de compartir tierras, pozos de agua y montes entre condue-

\footnotetext{
1 jfarberman@gmail.com, ORCID iD: https://orcid.org/0000-0003-4273-9009.
} 
ños inicialmente vinculados por lazos de parentesco ${ }^{2}$. Más precisamente $-\mathrm{y}$ sirviéndome sobre todo de litigios por tierras - he de profundizar en tres cuestiones: la de la racionalidad de este «modo alternativo de poseer», la de la conformación de la membresía que gozaba de derechos de propiedad y la de las jerarquías internas en los campos comunes ${ }^{3}$.

Entre las reflexiones más interesantes sobre la propiedad colectiva, se destacan las provenientes de una renovada historia del derecho, capaz de dialogar con la historia social y agraria. Su punto de partida ha sido la consideración de la propiedad como relación social y la aceptación de la existencia de una pluralidad de formas de poseer que el individualismo agrario y la codificación decimonónica invisibilizaron ${ }^{4}$. Así, a la noción «individualista y potestativa» de la propiedad moderna, se oponían las formas colectivas enraizadas en una antropología jurídica centrada en la cosa y no en el sujeto. Más aún, siguiendo a Grossi, la propiedad colectiva tenía «muy poco de propiedad» para ser esencialmente «un 'estatuto de la cosa', delimitando de esta suerte diversos grados de pertenencia sobre ella que ponían el goce del bien por encima de su dominio ${ }^{5}$. En este contexto, la propiedad colectiva bien puede considerarse «una entidad fraccionable, admitiéndose la legitimidad de más de un propietario sobre la misma cosa $»^{6}$.

Hoy sabemos que la propiedad indivisa (no necesariamente colectiva) se encontró relativamente difundida en el territorio hoy argentino - en particular en el noroeste- - asumiendo tres formas principales: el mayorazgo, el pueblo de indios y el campo común. Mientras el mayorazgo fue excepcional, pueblos de indios existieron en todas las cabeceras del Tucumán y sobre ellos existe

2 En este artículo utilizaré los términos mancomún, propiedad indivisa y campo común o comunero, como sinónimos en el sentido que acabo de sugerir. El término condominio, en cambio, sólo aparece a fines del siglo XIX y se generaliza en el siguiente. La conceptualización de Paolo Grossi resulta particularmente apropiada para pensar este paradigma «representado por las comuniones familiares y suprafamiliares, en el que la pertenencia de los bienes es atribuida a una comunidad viviente en la historia de manera ininterrumpida y concretada en formas organizativas también muy complejas de gestión de los bienes comunes» (traducción mía). Grossi, 1990: 507.

3 Grossi, 1981.

${ }^{4}$ En palabras de Congost, 2007: 21, «hay que comprender que la dinámica social de la propiedad conlleva la transformación, mutación y creación de nuevas especies de derechos de propiedad, que en el momento de su creación no disponen de seguridad jurídica, lo que no impide a veces su auge y consolidación (y más tarde su protección o su represión) y que revelan muchas veces cambios sustanciales en la evolución y transformación de los grupos sociales».

5 Grossi, 1992: 28.

6 Grossi, 1990: 28. Traducción mía. 
una profusa bibliografía ${ }^{7}$. En cambio, los campos comunes, derivados de las mismas prácticas campesinas, han sido objeto de menor atención no obstante mantengan su vigencia en algunas provincias ${ }^{8}$.

Aunque desconocemos por el momento la evolución en el tiempo de los campos comunes santiagueños, intuimos que fue ganando preeminencia a lo largo del siglo XIX ${ }^{9}$. De nuestra prospección en el archivo provincial (amén que de la profusión de los «parajes de un mismo apellido» en la cartografía), se desprende su significativa difusión en las costas del río Dulce, muy especialmente en las zonas de bañados situadas al sur de la ciudad capital e inmediatamente al norte de aquélla (en los futuros departamentos de Robles, Banda y Giménez, véase mapa 1).

7 Entre otras contribuciones, ver Tell, 2010: s/p; 2011: 201-221; 2015: 67-85. López y Bascary, 1998: 71-112. López, 2006: 215-238. Fandos, 2007: s/p. Sobre los mayorazgos riojanos, Boixadós, 1999: 51-78. Boixadós y Farberman, 2015: 19-46.

8 En particular en las provincias de Tucumán, Catamarca, La Rioja y Santiago del Estero. Sobre Tucumán, ver Doro, 1974. Sobre La Rioja, Consejo Federal de Inversiones, 1964. Y sobre Catamarca, Zubrzycki, 2002: 1-13; 2003: 19-27. Recientemente, Cristina López ha publicado un artículo sobre los campos comunes tucumanos durante la colonia, línea de investigación que esperamos continúe explorando. López, 2015: 80-100. Por nuestra parte, estudiamos la génesis de las llamadas «mercedes» en Los Llanos de La Rioja. Véase Boixadós y Farberman, 2011: 41-70. También Farberman, 2013: 607-640. Gracias a la existencia de un corpus documental muy variado, propusimos un conjunto de hipótesis que relacionaban los procesos de poblamiento del siglo XVIII y la formación de la propiedad indivisa. A nuestro juicio, en Los Llanos la imposibilidad de colonizar nuevas aguadas había cristalizado en estructuras agrarias y demográficas abigarradas, en las que convivían las familias poseedoras con otras numerosas de agregados. Los campos comuneros llanistos también fueron investigados, antes de nosotras, para períodos posteriores: Gabriela Olivera y Ariel de la Fuente lograron reconstruir la dinámica de transferencia de las mercedes a través de derechos y acciones, cuando el campo común conformaba la estructura agraria dominante, De la Fuente, 2007. Olivera, 2000.

9 Hebe Vessuri menciona que, para el siglo XX, los condominios santiagueños originados «cuando el predio es una única extensión de terreno que es impráctico subdividir» permiten la «explotación a favor de la colectividad de herederos quienes comparten, no la propiedad, sino sus ganancias. Pero esto es usualmente sólo una solución transitoria cuando la tasa de ganancia obtenida de la fuente no es suficiente para satisfacer las necesidades del condominio». Vessuri, 1972a: 41. Los condominios de referencia parecen ser exclusivos de los grupos propietarios de las fincas tradicionales, una de las cuales se estudia en profundidad en este informe. Yuraj Tacu se mantuvo en ese régimen entre 1921 y 1958, disolviéndose luego por desacuerdos entre los herederos. Cabe destacar que en el Censo Nacional Agropecuario de 1988 se registraban todavía 901 explotaciones agropecuarias «de ocupantes en campos comuneros» (cerca del 10\% del total de las explotaciones campesinas de «ocupantes»). No obstante, no podemos asumir que estos condominios contemporáneos funcionaran de manera similar a los del pasado. Tasso, 1997: 48. 


\section{Mapa 1. Campos COMUnes}

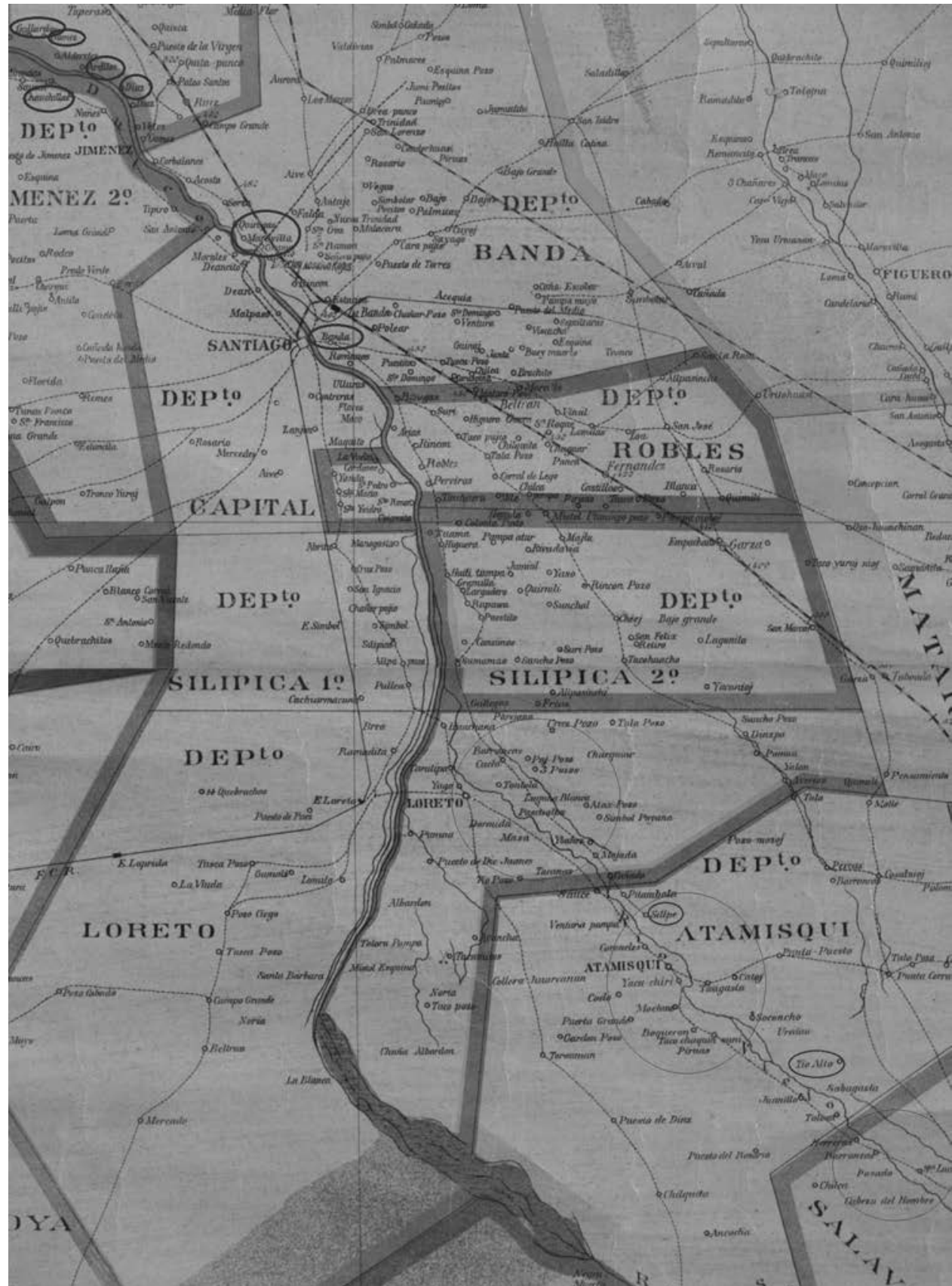

Revista de Indias, 2019, vol. LXXIX, n. ${ }^{\circ}$ 275, 111-142, ISSN: 0034-8341

https://doi.org/10.3989/revindias.2019.004 
También son abundantes, si bien para el siglo XIX, los rastros documentales relativos a la porción serrana de la provincia - que no abordaremos aquí- mientras que parecen escasos en la región del Salado, fronteriza y de población inestable ${ }^{10}$. No obstante lo dicho, la historiografía santiagueña ha tendido a privilegiar los lazos verticales de patronazgo en su análisis del mundo rural de la provincia, quizás extrapolando una difundida imagen de una mal conocida estancia colonial. Sin negar, la existencia de robustas jerarquías - presentes, por otra parte, también en el interior de los campos comunes- es nuestro interés indagar por los componentes que cooperaron a la conformación de una auténtica cultura comunal de la que todavía pueden observarse algunos rasgos en la región ${ }^{11}$.

Entendido el carácter aún exploratorio de mi investigación, intentaré en este artículo formular un conjunto de preguntas, conjeturas e hipótesis, a manera de agenda, que se irán desgranando a partir de ejemplos. Nada mejor entonces que comenzar con uno - don Ventura Días, residente en 1798 «en el paraje nombrado de su mesmo apellido»- para presentar brevemente el problema de la mancomunión y de las relaciones internas que se le asociaban ${ }^{12}$. Muchos de los vecinos de don Ventura habrían podido suscribir igual afirmación: cerca de «Los Días», se hallaban los parajes de «Los Morales», «Los Sánchez», «Los Ximénez», «Los Corvalanes»y «Los Gomes», topónimos todos que recordaban a los fundadores de estancias y chacras y a sus descendientes.

El primer Días recalado en el «paraje de su apellido» había sido un tal Pascual, abuelo de Ventura y beneficiario de una merced en 1695. Sin embargo, los Días podían jactarse de una presencia aún más antigua y remontarse al bisabuelo de Ventura, que le había cedido a su yerno una porción de su estancia. Transcurrido un siglo, el clan de los Días se había extendido y don Ventura representaba a nada menos que 19 jefes de familia, mujeres y varones, todos «compartes»y genéricamente reconocidos como sobrinos por el apoderado ${ }^{13}$.

10 En el Salado santiagueño la conformación de derechos de propiedad parece haber sido diferente aunque sólo existen trabajos para la segunda mitad del siglo XIX. Ver al respecto Rossi y Rízolo, 2009: 215-258. Y Rossi y Banzato, 2011: 133-162.

11 De ello ha dejado abundante testimonio la investigación folclórica. Ver por ejemplo el monumental trabajo de Di Lullo, 1943, paradójicamente fundador de la visión historiográfica que critico.

12 Goitía Francisca y Ventura Díaz. Sobre derecho a la estancia Los Gomes, 1798, Archivo Histórico de Santiago del Estero, Santiago del Estero (AHSDE), Tribunales, legajo12 bis, exp. 66.

13 Los compartes eran Ana Rosa y Felipa Sánchez, Vicente Días, Santiago, Alberto, Bartolo y Valentín Ximenez, Jorge Sanchez, Ventura, Juan Pablo y Josep Lorenzo Gonzalez, Isidro Díaz, Ramón Quiroga, Francisca y Bernarda Dias, Marcela y ClaraXimenez, Maria 
En 1798 los Días se enfrentaron con sus vecinos los Gomes en un pleito civil que se prolongó hasta 1802 . No era la primera vez que las dos familias litigaban: a fines del siglo XVII, el abuelo Pascual Días había sido lanzado de su estancia por el patriarca de sus rivales, Francisco Gomes. Cien años después, a raíz de una mensura discutida, las hermanas Ana Rosa y Felipa Sánchez (de Los Días) eran conminadas por doña Francisca Goytía (significativamente apodada "Goya Gomes») a manifestar sus instrumentos para probar sus derechos. Fue así que las antiguas escrituras y los papeles de ambas partes circularon entre Santiago del Estero y Buenos Aires y entre el cabildo local y la audiencia, hasta que la sentencia se decidió a favor de Los Días. Como era habitual, los vecinos colindantes participaron como actores de reparto, convocados para recordar la historia de las propiedades, la ubicación de carcomidos mojones y de remotos conflictos.

El caso de los Días nos permite introducir las tres cuestiones antes planteadas. Ante todo, ¿por qué motivos los condueños habían mantenido indivisa la estancia por un siglo? Varios testigos respondieron a esta pregunta: la mancomunión se mantenía por «ser muchos» los coherederos. En otras palabras, sólo impidiendo la fragmentación del patrimonio era posible sustentar a todos. Esta explicación, sin embargo, podía ser válida para un determinado momento del ciclo de vida de la comunidad de parentesco y no para otros, lo que nos plantea el problema de la racionalidad de esta práctica.

Nuestro ejemplo nos interpela también por la membresía en los campos comunes. Sin duda, eran «parte» de Los Días los 19 jefes de familia representados por don Ventura y también - aunque habría que precisar en qué grado- los cónyuges e hijos, las viudas o viudos de los coherederos y otros parientes que mantenían derechos en la estancia. El matrimonio podía señalar la partida de hombres y mujeres (no encontramos un patrón regular matri o patrilocal) y, aunque podemos presumir la existencia de negociaciones entre coherederos, seguramente seguían siendo numerosos los habilitados para retornar un día al lugar de sus mayores. A la vez, la residencia por sí sola tampoco aseguraba ser «parte»: además de los coherederos moraban en las propiedades indivisas agregados y arrendatarios. En este sentido, no es casual que tres ítemes de una información de testigos exigidas por don Ventura remitieran a la oposición dueño/ agregado:

Si sabe... que las dhas tierras que heredamos de ntros padres y abuelos respectivamente aunque se hallan proindivisas o que alguno de los Gomes nos ubiese

Isidora Dias, Maria Juana Gonzalez y Lucía Sánchez. Ximenez, Sáchez y Quiroga daban nombre a otros tantos parajes de la zona, AHSDE, Tribunales, legajo12 bis, exp. 66, f. 2 vta. 
admitido o sus maiores en calidad de agregados; si sabe... que alguna de ntras partes haya servido rendido algún obsequio o pensión alguna anual a los dichos; si sabe que es costumbre hacer de las cosas dichas los agregados con los dueños de las tierras que pueblan y cultivan.

Que quedara claro: los Días eran señores en sus tierras porque contaban con antiguos títulos gestionados por su fundador que les garantizaban autonomía y arraigo. Por el contrario, a los agregados apenas si se los toleraba a cambio del trabajo (o del arriendo) con que eventualmente contribuían. Los propietarios podían lanzarlos si no estaban satisfechos: a diferencia de la de los dueños, la condición de un agregado era vulnerable y provisoria.

Ahora bien, la mancomunión tampoco implicaba igualdad entre los compartes. Aunque las jerarquias no siempre resulten transparentes, la descendencia de las «líneas principales», el género, las capacidades de liderazgo, la edad y la legitimidad de nacimiento, entre otras variables, marcaban las relaciones de autoridad. No se trataba de utópicas comunidades de iguales: las relaciones de poder permeaban la convivencia, generaban disputas e incluso podían culminar en la disolución del campo común. ¿Por qué razones era Ventura y no otro quien representaba a los condueños? ¿Qué lugar ocupaban los parientes políticos o las ramas bastardas? ¿Y qué condiciones les tocaban a quienes no eran parientes o lo eran tan lejanos que sus derechos no eran considerados?

\section{TÉRMINOS Y RAZONES DEL MANCOMÚN}

Como anticipamos, en Santiago del Estero la mancomunión se difundió en las costas del río Dulce, lo que nos advierte sobre la posible intervención de variables ecológicas y demográficas ${ }^{14}$. Por ahora, identificamos dos grandes zonas de campos comunes diferenciadas ambientalmente: una al norte y otra al sur de la ciudad (ver mapa 1). En el siglo XVIII, la primera integraba el dilatado curato rectoral (futuros departamentos de Robles, Jiménez y La Banda) y comenzaba a unos $50 \mathrm{~km}$ río arriba de la capital, a mitad de camino entre ésta y el Río Hondo. Al oeste, se ubicaban los parajes de Jiménez, Chauchillas y el pueblo de indios de Tipiro mientras que, en la otra orilla, se localizaban las estancias de Quiroga y Maravilla. Los parajes de Los Días y los Gomes se situaban en el departamento de Jiménez I. En todo caso, esta subre-

${ }^{14}$ En la sierra santiagueña, como se dijo antes, el mancomún pudo ser una forma de poseer dominante pero los materiales de archivo sólo abundan para el siglo XIX. Vistas que las condiciones ecológicas de esa zona son muy diferentes, hemos decidido aplazar la investigación de la sierra para un futuro próximo. 
gión se encontraba alejada de los esteros que daban nombre a la ciudad aunque disponía de buenas pasturas, favorecidas por vertientes y ojos de agua ${ }^{15}$ (Fazio, 1899: 34). También la actual ciudad de La Banda y sus alrededores entrarían en primera zona y, como veremos, son varios los pleitos que nos conducen allí.

La segunda subregión es la de los bañados, franja alargada que se extendía al sur de la capital, incluyendo las poblaciones de Loreto, Soconcho, Atamisqui y Salavina. Esta zona - de nutridos pueblos de indios- se inundaba durante las crecientes estivales, habilitando una agricultura de altísimos rendimientos. El «clásico país de los bañados» se desparramaba en varios «distritos superpoblados» —como aún en el siglo XX los caracterizara Pierre Denis- que en 1778 concentraban más de un tercio de la población santiagueña ${ }^{16}$. Silvia Palomeque estudió con detalle la agricultura de bañados, siempre necesitada de permanentes trabajos de drenaje y deudora de la prodigalidad del monte chaqueño que le aportaba sombra y nutrientes ${ }^{17}$. Los expedientes que consideraremos nos conducen a las cercanías de Loreto y Atamisqui, aunque también en Salavina existió la mancomunión.

Vayamos ahora a los pleitos coloniales. El primero fue iniciado por don Manuel del Castaño, influyente vecino y propietario de la estancia Maravilla, a cuatro leguas de la ciudad. Del Castaño reclamaba a los Quirogas (representados por la viuda Manuela de Hoyos) la clausura del callejón abierto para separar las dos estancias y la destrucción de los cercos que protegían tres pozos de agua ${ }^{18}$. A diferencia de los Quirogas, Del Castaño no residía en su estancia - que había heredado apenas doce años antes del pleito- y tampoco la compartía. Así, el pleito enfrentaba a un propietario individual —on excelentes conexiones políticas - con diez compartes que ni siquiera sabían firmar. Sin embargo, el argumento de Del Castaño giró en torno de una interpretación abusiva de la mancomunidad fundada en un compromiso escrito y firmado en 1699 por «los principales señores de ambos terrenos». Dichos «señores» se llamaban Tomás de Quiroga — comprador de la estancia de su apellido a la orden de Santo Domingo - y Pedro de Vega y Frías — vendedor en fecha incierta del cuarto de legua de Maravilla al abuelo de Del Castaño-.

15 Fazio, 1899: 34.

16 La referencia al «país de los bañados» pertenece a Pierre Denis, que recorrió la zona hacia 1920 (Denis, 1987: 137). Para entonces, la población de la zona aportaba mano de obra a los obrajes forestales y a la producción a de azúcar. Sobre la población colonial en Santiago del Estero y el Tucumán, ver el censo del obispado del Tucumán 1778 en Larrouy, 1923.

17 Palomeque, 1992: 9-61.

18 Del Castaño Manuel contra Manuela Hoyos sobre la estancia Maravilla, 1797, AHSDE, Tribunales, legajo 6, exp. 105. 
La existencia misma de un compromiso entre vecinos, sin intervención de autoridad alguna, nos parece notable, así como la intención de los firmantes de que su validez rigiera en el futuro. Es un ejemplo elocuente de un derecho de propiedad concerniente a la cosa y no al individuo, además de pactado desde abajo. Su objetivo explícito era evitar potenciales pleitos a causa de los cambios de curso del río, garantizando a ambas partes el derecho al agua. Estipulaba que

... si con el transcurso del tiempo y robos de avenidas del río o pr otro cualquiera accidente las aguas favorecieren más mi jurisdicción que la del dho Pedro de Vega o pr el contrario más la del dho que la mía, no pr eso alguno de los dos ha de vedar ni impedir ni estorbar el uso de dhas aguas al otro y también es condición qe, si en alguna parte o en el todo de este compromiso y escritura de él alguno de los otorgantes quisiere faltar en algún tiempo introduciendo nuevos dros y acciones, ha de perder y pagar al otro trescientos pesos de a ocho reales el peso».

La letra del documento era clara. Sin embargo, la interesada lectura de don Manuel del Castaño distorsionó sus términos, proponiendo a Maravilla y Los Quirogas como una misma unidad productiva regida por la mancomunión:

Todos estos años que han poseído mis antepasados y otros tantos los de los Quirogas han corrido bajo de un compromiso de mancomunidad que hicieron nuestros ascendientes en todas las comodidades qe tenían por entonces y adelante pudieran tener las dhas estancias de manera que de dos estancias diferentes las redujeron a una sola con la única diferencia que fuesen gobernadas de dos distintos pobladores (itálica nuestra), con tal circunstancia, qe si a uno de ellos le acomodaba pasar sus hasiendas al otro terreno no pudiese en ninguna manera impedirle el otro.

No era todo: siguiendo al querellante, la supuesta mancomunidad impedía a sus vecinos cercar los pozos (que él consideraba «producciones de la naturaleza») y colocar mojones.

Del Castaño era poderoso y logró que la justicia capitular ordenara prenderle fuego a «los tres pozos cercados llamados Puestito, Quichca y Cosme», advirtiendo además a los Quirogas sobre «la inutilidad del callejón que ellos abrieron junto al de Dn Manuel del Castaño» ${ }^{19}$. Sin embargo, los Quirogas, además de resistir las órdenes y cercar nuevamente los pozos, siguieron dando batalla y argumentando sobre los alcances del compromiso

19 En 1808 don Manuel del Castaño era capitán de las milicias regladas de la ciudad y en varias oportunidades se había desempeñado como regidor y alcalde. Por otra parte, la expulsión de los jesuitas le permitió hacer grandes negocios con los bienes de temporalidades. 
de 1699. Según ellos, lo que debía compartirse con los propietarios de Maravilla era solamente el corto trecho de la bajada del río «porqe las crecientes... fuesen contingentes y mudables». Por el contrario, los pozos de agua - tan preciosos que ameritaban un nombre - se hallaban en el centro de la estancia y habían sido «trabajados a expensas de mis compartes» sin que Del Castaño participara. Notemos que, para don Ventura Quiroga, la mancomunión comprendía también el trabajo - al menos este tipo de trabajode los comuneros.

Los Quirogas perdieron la exclusividad sobre sus pozos entre 1808 y 1809 , para recuperarla posteriormente tras apelar a la Audiencia ${ }^{20}$. Sin embargo, lo que nos interesa es la luz que los alegatos de ambas partes arrojan sobre las prácticas de los comuneros, generalmente silenciadas y naturalizadas. Ya que, por absurdas que fueran las pretensiones de Del Castaño, parece verosímil la descripción de lo que estaba en juego en la mancomunión.

¿Qué se compartía en Los Quirogas? Con seguridad, los tres pozos de agua así como el trabajo de limpiarlos, mantenerlos y cercarlos. La libre circulación del ganado - que Del Castaño reclamaba entre las dos unidades - era seguramente un hecho en Los Quirogas y es probable que también las «comodidades» (pozos, represas, atahonas, corrales y depósitos) fueran comunes. Entendemos que la gestión conjunta de estos bienes era la que hacía de los Quirogas «dueños» y no «inquilinos» y les aseguraba el gobierno de los agregados que probablemente tuvieran en su arrimo.

¿Qué ocurría con los animales, los rastrojos, las cosechas? Nada se dice sobre el particular en este pleito. Se nos permitirá pues desarrollar un par de ejemplos — uno de la zona de bañados y el otro fuera de la misma- para acercarnos al problema.

En 1787, la viuda Rosa Villavicencio del paraje de Los Sauces (vecino a Loreto) denunció ante la justicia a su yerno Antonio Cárdenas por arrogarse pretensiones sobre el terreno que le habían «cedido» para sembrar ${ }^{21}$. Una vez más, una mujer aparece a la cabeza del campo común, en este caso como propietaria exclusiva de la mitad de las tierras de Los Sauces - una legua comprada durante su matrimonio, tres o cuatro décadas antes del pleito- y partícipe de las «por partir». Sin embargo, como las tierras de Los Sauces no eran aptas para la agricultura, la familia había agregado otras, denominadas «Potrero de Villalba». Era en aquel sitio donde, según Rosa,

${ }^{20}$ Naturalmente, éste — que devino en jefe de los ejércitos patriotas en 1810 - siguió insistiendo y en 1815 su esposa trataba de reabrir la causa, aparentemente sin éxito.

${ }^{21}$ Rosa Villavicencio. Sobre separación de bienes, 1773, AHSDE, Tribunales, legajo 3, exp. 27. 
... así yo como los enunciados mis hijos tenemos y hemos tenido en comunidad casas y rastrojos pa el efecto dicho, cuio motivo relevante permanece hasta oy, sin embargo hallarse dos de mis hijos emancipados desde en vida de mi marido.

La gestión comunitaria se refiere siempre a este sector específico y asociado a la actividad agrícola, que podemos suponer beneficiada por las inundaciones del río. Con total ingratitud, seguía Rosa, Cárdenas pretendía ahora

... cuartarlas sin más causa ni motivo que su mero antojo, queriéndose hacer dueño absoluto de aquella situación, siendo así tiene en ntra inmediación la casa de su vivienda y otros rastrojos a lado de afuera sin que nadie le embarase... como si sola fuese única heredera su mujer... sin hacerse cargo del gravísimo perjuicio que nos originaría en cederle a él lo que pretende sin hacerse cargo al mismo tpo qe aun me hallo viva y la mitad de esta compra me pertenece a mí y tan solam.te la otra mitad está indivisa y por partir.

De esta jugosa cita me interesa lo ya referido a la sectorización del campo y a la tensión entre la normativa y las prácticas. Por un lado, la afirmación de la existencia de otros rastrojos cultivados ¿exclusivamente? por Cárdenas, fuera del Potrero de Villalba. En segundo lugar, la apelación a las leyes de herencia, que la viuda no ignoraba: aunque usara las tierras en mancomún con sus hijos, a Rosa le pertenecía la mitad, lo que dejaba en sus manos decisiones que a todos afectaban ${ }^{22}$. Para resolver el conflicto, la viuda proponía, o bien cederle a su hija la parcela que le tocaba (siempre que se hallara fuera del potrero de Villalba), o bien entregarle dinero en efectivo una vez realizada la «justa tasación» de las tierras.

Al parecer, algún arreglo extrajudicial existió entre los cuñados ya que, luego de ser reconvenido Cárdenas por el alcalde de Hermandad, doña Rosa se echó atrás. En presencia de los interesados y de la autoridad, sostuvo que ella

... no pedía nada contra su ierno, ni quitarle el rastrojo nombrado Villalba $p r$ que era su trabajo, (cursiva nuestra) ni tampoco dice qe sea perturbador ni que aia querido lanzarlos de este lugar... lo qe únicamente pide es que vivan en comunidad y hermandad.

El pronunciamiento de las justicias a favor de la continuidad de las prácticas comunitarias en el potrero de Villalba confirmaba la intención de man-

22 Probablemente fuera doña Rosa la «dueña principal» de Los Sauces. No sólo por su mayor participación en una eventual división del campo sino por ejercer la jefatura de la familia. 
tener el siempre precario equilibrio entre la «hermandad» — sustanciada en el derecho a sembrar de mancomún, la ausencia de cercos y la libre circulación del ganado dentro de las tierras comunes - y el cálculo del trabajo de cada cual, implícito en la apropiación individual de la cosecha ${ }^{23}$. En este sentido, se disponía

... qe desde la fha de este día usen y siembren dho lugar nombrado Villalva entre todas las partes, sin perturbar ni impedirse unos con otros, sino que precisa e indispensablemente tenga cada cual en dho lugar su rastrojo libremente sin que uno ni ninguno impidan, cerquen con potreros ni atajen las sendas o caminos precisos para el tráfico y entrada de ellos.

El litigio entre doña Josefa Corvalán y don Felipe Argañaraz - marido de su hija Isidora - tiene mucho en común con el que acabamos de describir aunque, como profundizaremos posteriormente, esta estructura agraria parece haber sido de mayor complejidad que el de Los Sauces/Villalba. Al igual que Rosa, también doña Josefa se ofreció a partir entre sus hijos las tierras de Silpe para evitar ulteriores desacuerdos con su yerno Felipe de Argañaraz. Sin embargo, Argañaraz resultó ser más ambicioso que Cárdenas y cuestionó el reparto realizado luego por su suegra - que lo apartaba del cerco en disputaa través de una presentación judicial ${ }^{24}$. Para «soportar el peso de su matrimonio» contraído dos años antes, decía Argañaraz,

... me dediqué a la agricultura en la estancia de Silpe perteneciente a dho mi padre político, que en comunidad gozaban los herederos el beneficio de ellas por estar indivisas y yo, como uno de ellos, fabriqué una guerta de algodón con gusto y beneplácito de todos los herederos y habiéndose propendido a las partijas de dhas tierras pedí justamente se me adjudicase en aquella parte donde tenía mi guerta ya con plantas frutales y no conformándose dha mi suegra la adjudicación en este modo se compromete más bien a pagar las plantas.

Disconforme frente a la tasación de su algodonal y a las hijuelas realizadas por la viuda «con depravada malicia», Argañaraz reclamaba al cabildo su justicia «como colindante y parte».

${ }^{23}$ Es posible que los verdaderos enemigos de Cárdenas fueran los hijos de Rosa, sus «hermanos políticos». No dudaba de ello el párroco que, a través de una carta dirigida a juez, alabó la «acreditada conducta y arreglado vivir» de Cárdenas, «sin qeaia oído alguna queja ni del más mínimo agregado, pues le consta a vmqe en el campo todo lo comunican con los curas o sus tenientes para qe estos consuelen e intercedan con los señores de las tierras y les muevan a piedad», AHSDE, Tribunales, legajo 3, exp. 27, f. 27.

${ }_{24}$ Argañaraz Felipe pide avaluación de un trabajo,1803, AHSDE, Tribunales, legajo 6, exp. 74 . 
En el próximo apartado regresaremos a Silpe y a sus compartes. Por ahora, nos limitaremos a recuperar de estos ejemplos las tensiones que la mancomunión introducía entre la ley la y la práctica, entre los parientes de sangre y los políticos y en la gestión misma de las labranzas. En este sentido, una cuestión crucial y que surge en los dos conflictos es la de la tirantez entre propiedad común y trabajo personal ya que, en última instancia, los reclamos de Cárdenas y Argañaraz (así como las compensaciones propuestas por las respectivas suegras) se fundaban en el cálculo del trabajo invertido en las sementeras. Algo equivalente podemos inferir sobre la propiedad del ganado, como lo señalarían los siguientes ejemplos.

Corría el año1798 cuando Manuel de Santillán, de «la otra Banda del río», le reclamó al alcalde de hermandad la devolución de las vacas y de las yeguas embargadas a su hijo preso $^{25}$. La objeción era que de aquellos animales - probablemente marcados con su hierro- el reo no tenía

... parte ni arte... porque son pertenecientes a mis seis hijas qe con su trabajo fabricaron dos ponchos y diez cinchadores labrados y remitieron a la de Santa $\mathrm{Fe}$ con dn Jf Ignacio Xerez pa qe redujera en animales y de facto así lo hizo hará cuatro o cinco años.

Por «haberlas comprado con sus trabajos, no tienen derecho mis hijos varones», sostuvo Santillán en referencia a las yeguas y vacas confiscadas, y se ofreció a presentar testigos para probarlo. La propiedad femenina del ganado ovino era habitual en Santiago, donde la tejeduría doméstica estaba en manos de las mujeres y la producción de ponchos era un rubro importante del comercio interregional. Sin embargo, las mujeres también podían hacer sus «inversiones» en ganado mayor y aunque no tuvieran su propio hierro, la propiedad individual les era reconocida.

El segundo ejemplo también concierne a los Santillán de «la otra banda del río» ${ }^{26}$. María López era viuda de Juan Santillán—que tenía tres hijos de un matrimonio anterior - mientras que Isabel Galván era la hijastra del difunto y esposa en segundas nupcias de su albacea Miguel Coronel. A este último le tocó abogar por las dos mujeres, ambas propietarias de algún ganado marcado con el hierro del difunto.

Los intereses de la viuda estaban protegidos en el testamento del marido. Allí se recordaba que los hijos del primer matrimonio de Santillán ya habían

${ }_{25}$ Costas Domingo contra Santillán Manuel sobre atropello, 1798, AHSDE, Tribunales, legajo 10 bis, exp. 55. 1798 .

26 Santillán Juan de. Sobre reclamo de la herencia de su padre, 1727, AHSDE, Tribunales, legajo 11 bis, exp. 57 bis. 
recibido su parte en vida del padre, mientras que las diez lecheras, tres tamberas, dos mulas, siete caballos, ocho yeguas y cuatro bueyes - en poder del albacea - pertenecían a María López «por ser adquiridos lo más de su cuidado y trabajo en tres años que hemos sido casados». En cambio, la situación de la hijastra Isabel era más compleja y requirió de una sumaria de testigos que probaran sus derechos. En efecto, de su primer marido, Isabel había heredado seis vacas y sus terneros, capital al que se habían sumado luego dos lecheras adquiridas durante su viudez. Aunque todos estos animales llevaban la marca de Santillán, los testigos le reconocían la propiedad a Isabel y, además de los derechos de la herencia sobre una parte del ganado, valoraban como prueba suficiente el trabajo de la mujer «amansando los novillos».

La suma de estos ejemplos nos proporciona una primera idea acerca de qué se compartía y qué se consideraba propiedad individual, amén de las tensiones entre las costumbres y las leyes. El trabajo invertido sostenía la lógica del disfrute individual de ciertos bienes (cosechas, ganado). ¿Qué lógica, en cambio, regía lo indiviso? Sin pretender agotar el tema, comencemos por buscar alguna respuesta en las (escasas por naturalizadas) explicaciones que articularon los condóminos mismos, o sus testigos.

Recordemos en primer lugar a nuestros ya familiares Días: según los testigos, si las tierras llevaban cien años indivisas era «por ser muchos» los condóminos. Impedir la fragmentación en zonas relativamente áridas y de escasas tierras arables o evadir los altos costos de los trámites sucesorios podían ser razones suficientes para la mancomunión. También intervenían la pérdida o deterioro de los títulos, su eventual inexistencia y la ausencia de mensuras. Así por ejemplo, en el testamento de Juana Rodríguez - vecina de Los Peraltas, en Salavina-, sólo se autorizaba a distribuir entre las hijas cuatro esclavos, un perchel de trigo, tres ponchos, un rastrojo sembrado y unos pocos animales ${ }^{27}$. Las tierras no se consignaban «por su cortedad y por ser pr lo mismo indivisibles entre las cuatro herederas, debiéndose añadir a esto el que los instrumentos se han perdido y se ignoran sus límites fijos».

El alejamiento del fantasma de la pobreza se adivina también en los dos casos siguientes. Agustín González —uno de los hijos de doña Rosa Villavicencio que el lector ya conoce - ordenó que sus bienes - una estancia, los enseres de la casa y algún ganado - se repartieran entre la viuda y sus ocho hijos $^{28}$. En cambio, la suerte de tierras de mil varas recibida de sus padres fue

27 Juana Rodríguez. Inventario y partición de sus bienes, 1803, AHSDE, Tribunales, legajo 1, exp. 19.

28 González Agustín. Su testamentaria, 1814, AHSDE, Tribunales, legajo 6, exp. 84. 
tasada en 100 pesos y apartada, amparándose en la figura del quinto de libre disposición. Este legado quedaba

... vinculado pa todos mis hijos y los que de ellos descendieren, de modo que viniendo a pobreza suma tengan todos donde recogerse, fabricar su habitación y usar de las tierras para sus labranzas y manutenciones sin que ninguno pueda enajenarlo ni empeñarlo en cantidad alguna porque es mi voluntad les sirva solo de hospital en sus indigencias, pa lo qe solo les cedo la posesión y usufructo, reservando la propiedad y el vínculo según derecho y usando del libre qe me compete en el remanente de mi quinto ${ }^{29}$.

No sólo los hijos encontrarían su «hospital» en aquellas tierras: también al huérfano que había criado se le aseguraba el disfrute temporario de las mismas, permitiéndosele «vivir y edificar rancho y sembrar llegando a maior edad en el terreno que dejo vinculado pa mis hijos y sus descendientes».

Las propiedades indivisas de Juana Rodríguez y Jacinto González, los padres de Agustín, se hallaban en la zona de bañados y parece tentador relacionar estructura agraria y condiciones ambientales. Los litigios ocasionados por el capricho del río, que un año favorecía a un vecino y el siguiente a otro, eran moneda corriente y quizás fuera más práctico compartir las fértiles «islas» que dividirlas para disputarlas permanentemente ${ }^{30}$. En otras palabras, el azar de las crecientes dificultaba el reparto, como parecía entenderlo Francisco Pereira, «del paraje nombrado de su apellido». Sus tierras «llamadas del Ciego», cinco leguas al sur de la ciudad, debían quedar «indivisas y porque puedan seguir viviendo todos, disfrutando de ellas en unión y conformidad y el que de esto se apartare pierda el dro que tuviera a dha estancia». La mancomunión de las mismas se justificaba en que algunos de los herederos quedarían «perjudicados por lo árido de algunas de ellas». Una vez más, la propiedad colectiva aparecía como un medio para restituir la equidad y la justicia que la naturaleza podía retacear.

En resumen, la mancomunión no regía necesariamente sobre la totalidad de los bienes existentes en una estancia y, mientras el disfrute del producto de las sementeras y el ganado solían ser individuales (si así se consideraba el trabajo invertido en ellas) pasturas, montes y pozos eran comunes. No solamente para los condueños, seguramente también para los agregados. Ello recuerda, a pesar de tratarse de un tipo específico de propiedad comunal, las reflexiones de Vassberg sobre los derechos y usos sobre tierras baldías y ad-

29 AHSDE, Tribunales, legajo 6, exp. 84, f. 306.

30 Este mismo problema era el que el Compromiso de 1699 invocado por don Manuel del Castaño en defensa de sus derechos sobre la estancia Maravilla pretendía resolver. 
vierte al historiador latinoamericanista sobre la extensa tradición comunal hispana trasladada a estos campos surgidos de mercedes ${ }^{31}$.

\section{MEMBRESÍAS Y JERARQUíAS}

Ya habrá notado el lector que la mancomunión no eliminaba las jerarquías entre los compartes. La representación en los pleitos nos ha proporcionado algunas pistas acerca de los «principales» de cada comunidad (probablemente los jefes de familia de cada casa) y de las decisiones que quedaban depositadas en ellos (organizar las eventuales partijas, aceptar a «huéspedes», huérfanos y agregados y gestionar las actividades económicas del campo común). Hemos descubierto asimismo que podían ser mujeres - viudas en nuestros ejemplos - las que asumieran ese papel $\mathrm{y}$, aunque sus derechos legales sobre la mitad de la herencia contribuyeran a su primacía, las causas eran, a nuestro entender, más profundas y estructurales. En efecto, la importancia económica del trabajo femenino - no sólo la textilería - en esta tierra de emigración que era Santiago del Estero apuntalaba organizaciones que bien podríamos calificar de «matriarcales» ${ }^{32}$.

Sin embargo, aunque el parentesco resultara una estructura importante del campo común, ser pariente era condición necesaria pero no suficiente para integrar la membresía con derechos plenos. De hecho, en las convocatorias de testigos proliferan quienes se reconocían emparentados con los litigantes aunque ignoraban el grado: claramente estos sujetos no eran parte ni lo pretendían. Entendemos que el núcleo de la comunidad indivisa era el que se reconocía como descendiente — como se sostuvo en un pleito- de «los principales troncos» que solían aportar su apellido como marca distintiva.

En este sentido, la propiedad mancomunada tenía su fundador - el comprador de la tierra o el beneficiario de una merced o donación - al que los condóminos se remitían, cual si se tratara de una figura mítica, para probar la «posesión inmemorial» que legitimaba su presencia en el lugar. Además de la memoria (que los testigos refrendaban), probaban el señorío la custodia de títulos añejos y, sobre todo, el poblamiento efectivo en las tierras asegurado por la residencia de los condóminos, la existencia de ranchos, instalaciones,

31 Vassberg, 1983: 25-54.

32 Ver Farberman, 1996: 33-59. Investigaciones etnográficas de Luis Garay muestran que en la sierra santiagueña las propiedades eran reconocidas por el nombre de las mujeres y que a menudo era el apellido por línea materna el que se utilizaba para reconocer a las familias. Luis Garay, comunicación personal. 
sementeras y hacienda. De esta manera, apellidos, sujetos, lugares y prácticas se entrelazaban en una densa red de sentidos.

Los pleitos civiles lo ilustran bien. El lector ya conoce a doña Francisca Goytía Gomes, la contrincante de don Ventura Días, cada uno «dueño principal» en el «paraje de su mismo apellido». Así como don Ventura y sus sobrinos hacían nacer su linaje en don Pascual Días (y secundariamente en el bisabuelo Morales), también doña Francisca se proclamaba «nieta y heredera por línea recta paterna» del capitán Francisco Gomes (de hecho, se la nombra alternativamente como Goytía y como Gomes). Para don Ventura Días, el mojón que una sobrina de Francisca había quemado para desafiarlo «demarcaba nuestro terruño y apellido».

Sin embargo, estas correspondencias podían cambiar con el tiempo y, así como era posible utilizar estratégicamente uno u otro apellido, también los lugares solían designarse con nombres diversos. Nos lo recuerdan los Lunas y los Noriegas, que desde fines del siglo XVII poblaban la zona de La Banda y que litigaron reiteradamente a pesar del parentesco que los unía. El fundador del campo común era don Antonio Luna, «benemérito de la guerra pendiente», quien en 1721 había comprado una legua y media de tierras en dos operaciones sucesivas ${ }^{33}$. Por mucho tiempo, la estancia allí reunida fue conocida como la de los «herederos de Antonio Luna» y allí habían crecido numerosos sus descendientes. En fecha incierta, Ignacia Luna, hija de Antonio, se casó con don Francisco Noriega, miembro de una familia con cierta antigüedad en la zona. Quizás por eso, o por la prolífica descendencia masculina, o porque los varones Luna se instalaron en casa de sus esposas, en algún momento las tierras de los «herederos de Antonio Luna» pasaron a denominarse «Los Noriegas».

Pero el cambio de nombre no modificó la opinión de Francisca Días (apodada significativamente Goya Noriega, remitiendo al apellido materno), que releyó la historia del lugar proclamando la primacía de los derechos de los Luna. En 1808, doña Francisca procuró demostrar (sin éxito) que hacía decenios que sus primos hermanos los Noriegas eran «tolerados» por los Luna, ya que de estos últimos provenía «la línea que hacía heredar». Según adujo, los Noriegas no descendían de doña Ignacia Luna, sino de la segunda esposa de Francisco Noriega, el abuelo común. Esto volvía a los Noriegas - por parientes que fueran y aun compartiendo su propio apellido materno - intrusos en el campo común fundado por Antonio Luna. Para concluir, basta agregar que,

33 Noriega José Javier contra doña Gregoria Díaz. Sobre mayor derecho a tierras en la banda del río, 1808, AHSDE, Tribunales, legajo 2, exp. 38. 
como las segundas nupcias de Francisco Noriega nunca pudieron comprobarse, el plan de la querellante naufragó y sus rivales pudieron asumirse «partes legítimas de la estancia de Los Noriegas».

Así pues, cuanto más directa fuera la ascendencia y continuada la residencia, más sólidos resultaban los derechos de membresía, al menos en situaciones de conflicto. Por eso, la estrategia de doña Francisca apuntaba a convertir en parientes políticos a quienes lo eran de sangre, subordinando a un segundo plano aquel apellido que demarcaba el «terruño». Lo que nos conduce a una espinosa cuestión ya esbozada en los ejemplos anteriores: la del papel y la jerarquía de los parientes políticos en el campo común.

El pleito que un grupo de compartes del paraje de Los Gallardos (al norte de la ciudad capital y no muy lejos del Río Hondo) inició contra Luis Ximenez por la posesión de una «isla» formada circunstancialmente por el río Dulce es transparente al respecto ${ }^{34}$. El «intruso» — calificado al inicio del escrito como «vecino de Chauchillas»— era evocado de manera más ajustada pocas líneas más abajo:

El motivo del nuevo dro. Qe (Ximenez) alega es el haber el río mudado de cauce impetuosamente y formado una isla, cortando nuestras tierras y la propiedad referidas. Hemos dicho mal sus tierras. Las de Chauchillas son del ciudadano Bernabé Paz y Ximenez no sabemos que sea un propietario, sino hermano político de aquel.

La ilegitimidad del reclamo de Ximénez, según sus contrincantes, se sustentaba en que el parentesco político no creaba derechos de propiedad en el campo común (a menos que Ximénez fuera un yerno bien avenido y representara a los Paz, cosa que ignoramos). Así pues, las mismas razones por las que Francisca Días cuestionaba a sus primos Noriega (aunque manipulara interesadamente los parentescos), reaparecían en el alegato de los compartes Gallardo para descalificar a sus vecinos.

En suma, como era previsible, las jerarquías del parentesco privilegiaban las líneas de descendencia directas - masculinas y femeninas - y subordinaban a los parientes políticos aunque «sembraran como un hermano más» (Felipe de Argañaraz dixit). Como elocuentemente dijera un vecino riojano en el siglo XVII, más que parientes los cuñados eran «accidentes» (Boixadós, 2001).

Pero también existían jerarquías entre los parientes de sangre. Patriarcas o matriarcas solían desempeñarse como «principales señores», recayendo en

34 Juicio seguido sobre derecho y posesión de un campo, 1811, AHSDE, Tribunales, legajo 2, exp. 65 . 
ellos el «gobierno» — que regía sobre los demás parientes, criados, esclavos y agregados - , oportunamente delegado en los coherederos juzgados más capaces. Un magnífico ejemplo nos lo proporcionan, una vez más, los condóminos de Silpe ${ }^{35}$. El lector recordará que, a causa de un disgusto con su yerno Felipe de Argañaraz, la viuda Josefa Corvalán había decidido repartir las tierras de la estancia entre sus hijos. Aunque la partija se realizó, no alcanzó a todos los bienes de la viuda que, supuestamente, poseía además tierras en la ciudad, alhajas y alguna hacienda legada por otros parientes. El caso es que, a la muerte de doña Josefa, el insidioso yerno apuntó contra uno de los hijos - Bartolomé Corvalán alias Lugones - que en vida de su madre se había ocupado del «gobierno» de una diversificada empresa familiar. Para demostrar la maliciosa gestión de su cuñado y acelerar el inventario de los demás bienes de su suegra, Argañaraz convocó a varios testigos cuyas declaraciones nos dejan una vívida pintura de las actividades y del manejo de la estancia de Silpe ${ }^{36}$.

Cabe destacar que Bartolomé era hijo natural de doña Josefa (de hecho, Argañaraz se complace en tacharlo de «bastardo» una y otra vez), lo que nos interpela sobre las ramas bastardas de los condominios y sobre la figura del criado, ya surgida en alguno de los pleitos, que se encontraba a mitad de camino entre la del hijo adoptivo y el agregado ${ }^{37}$. Es significativo en este sentido que los testigos, como reconociendo su status ambiguo, oscilaran en nombrar a Bartolo por su apellido (Corvalán) y por su alias (Lugones).

Según los declarantes, hasta encontrarse en condiciones de «buscar de por sí», Bartolo Corvalán Lugones y otro hermano bastardo habían sido «vestidos y mantenidos» por la madre y las hermanas «con sus trabajos personales y bienes de ellas». Ignoramos a qué edad pudo Bartolo Corvalán «buscar de por sí», pero es seguro que a la muerte de Pedro Josef Lugones, hijo legítimo de Josefa Corvalán y encargado de la gestión del campo, Bartolo ocupó su lugar, para evidente fastidio de su cuñado. En efecto, las preguntas de la sumaria

${ }^{35}$ Corbalán Josefa contra German Lugones sobre nulidad de una mensura en Silpe, 1803, AHSDE, Tribunales, legajo 16, exp. 8.

36 Una mensura de 1915 de la propiedad colindante de Garciano (condominio) nos muestra que para esa fecha Silpe seguía aún indivisa. Se la remite a «los Lugones». No demasiado lejos, figura también Los Sauces, «lote de Juana Corvalán». Mensura de Garciano, 1915, AHSDE, Tribunales, legajo 690, exp. 9.

37 Según Argañaraz, don Bartolomé Lugones «asimismo alega que en partijas extrajudiciales se le adjudicó a la finada mi madre política como a uno de los demás herederos». La insolencia del bastardo consistía en pretender ser tenido por legítimo a los efectos de la herencia. Corbalán Josefa contra German Lugones sobre nulidad de una mensura en Silpe, 1803, AHSDE, Tribunales, legajo 16, exp. 8, f. 23. 
buscaban estigmatizar a Bartolo como un administrador ineficiente e ilegítimo. Previsiblemente, la mayor parte de los testigos secundó a Argañaraz, coincidiendo en que «dho bastardo dn Bartolo Lugones» era «dueño y absoluto de dha estancia y sus bienes y agregados de ella». Sólo una voz discordante sostuvo que, en la práctica, «este tal no gobernaba casa ni sus agregados sino qe en esto solamente hacía y disponía lo que la madre le mandaba».

Tratándose de la viuda Corvalán, mujer de armas tomar como hemos comprobado, quizás este solitario testimonio fuera el más cercano a la verdad ${ }^{38}$. Como sea, lo cierto es que Bartolo aparece ocupándose de variadas tareas, lo que habla de la complejidad de su empresa familiar. Además de las declaraciones, los recibos adjuntados al expediente lo señalan pagando jornales, recibiendo y comerciando tejidos, supervisando la construcción de carretas, contratando carpinteros, organizando el trabajo de los agregados. «Mandando y gobernando», en otras palabras, ya fuera como cabeza del condominio o como delegado de su madre.

Mientras Bartolo permaneció soltero, trabajó al servicio de su casa. Se trataba de una regla básica en el mundo rural: si su madre y hermanas (significativamente nunca se menciona a los varones Lugones) lo habían mantenido durante su niñez, lo esperable era que de adulto ayudara a acrecentar el patrimonio familiar. Y esto era lo que Argañaraz deseaba poner en duda, al sugerir que Bartolo hacía sus propios negocios traicionando la debida reciprocidad. Aunque el expediente está inconcluso, sabemos que Bartolo se alejó de Silpe a partir de su matrimonio. Según los testigos, la novia no fue del gusto de su madre y hermanas y por «su sentimiento» Bartolo pasó al refugio de don Ignacio Priego, vecino de Pitambalá, su suegro y representante legal en este pleito.

¿Qué ilustran estos casos sobre las jerarquías internas al campo común? Que no eran comunidades igualitarias pero también que, incluso existiendo «dueños principales»y hasta verdaderos administradores, era preciso reunir consensos para la toma de las decisiones más importantes. Por ejemplo, en el pleito entre los Gómez y los Días, los testigos registraron el desacuerdo entre Ventura y sus «sobrinos» al realizarse la mensura. «Las mujeres que en aquella sazón se hallaban en la casa» se aferraron de la cuerda del agrimensor y «en medio del bullicio y del llanto» el comparte Vicente Sánchez afirmó que «si el tío Ventura Díaz piensa pasar por esta posesión, io desde luego la contradigo» (Ventura les había pedido a sus parientes que «dejaran hacer»al

38 Aunque ese testimonio fue luego considerado parcial por la influencia de Priego, suegro y representante de Bartolo Lugones. Alejandro Lugones, el testigo, era también cuñado de Priego, AHSDE, Tribunales, legajo 16, exp. 8, f. 23. 
funcionario del cabildo para discutirlo en un segundo tiempo). El consenso logrado al respecto se advierte en el hecho de que entre los 19 representados que firman al final figuraban tanto Ventura Díaz como Vicente Sánchez.

\section{LOS AGREGADOS}

Más allá de los «dueños», orbitando en las orillas de los círculos concéntricos de la reciprocidad, estaban los agregados. Los hemos entrevisto apenas en los pleitos ya que carecían de representación por no ser parte. Eran, por el contrario, dependientes, ya fuera de propietarios individuales o colectivos -incluidos los pueblos de indios - , una masa flotante y probablemente numerosa, presumiblemente en crecimiento durante el siglo XIX ${ }^{39}$.

Como es sabido, la figura del agregado puede rastrearse a escala continental, en ámbitos rurales y urbanos, durante la colonia y el siglo XIX, denotando dos sentidos principales: dificultades para la instalación autónoma y acumulación de fuerza de trabajo para el grupo familiar de recepción. Por ello, es congruente que en la actual Argentina los agregados escasearan en la región pampeana - donde el acceso a tierras era relativamente más sencillo durante la colonia- y fueran numerosos en determinadas zonas del interior. Sin embargo, más allá de su contenido general — dependencia personal y acceso a tierras ajenas - el desafío consiste en descubrir las particularidades regionales y temporales de la agregaduría, además de su peso relativo en las estructuras agrarias.

Nos encontramos bastante lejos de alcanzar ese objetivo. Sabemos que en Santiago del Estero la agregaduría fue común en el siglo XIX, pero las precisiones sobre el contenido concreto del vínculo suelen ser impresionistas y románticas. El sagaz memorialista Lorenzo Fazio lo asoció con la gran propiedad, diferenciándolo del arrendamiento que, según sostenía, «no se acostumbraba» en la provincia ${ }^{40}$. Sin embargo, la información que nos aportan los pleitos - bien que para una centuria antes y en un paisaje agrario algo diferente - podría relativizar tal asociación, sugiriendo una difusión mucho más amplia de la agregaduría, al menos en la zona de bañados ${ }^{41}$. De hecho, Silvia

39 Ya que las fuentes que los registran como tales son predominantemente decimonónicas. Este tema precisa urgente investigación.

40 Fazio, 1898: 283.

41 Palomeque pone en duda las conclusiones de Fazio, aún para fines del siglo XIX. Rescatando la información de Alejandro Gancedo, destaca el peso de los pequeños propietarios ganaderos que controlaban en esos años casi un $40 \%$ de la tierra y los ocupantes de tierras 
Palomeque y Alberto Tasso encontraron en los agregados $-\mathrm{y}$ el último autor también en los arrendatarios - un actor fundamental para comprender el mercado de trabajo en el Santiago decimonónico, subrayando asimismo el paternalismo intrínseco a esta relación social ${ }^{42}$.

Por nuestra parte, conseguimos ponerle números al universo de los agregados utilizando un padrón levantado en 1819 en Salavina ${ }^{43}$. Encontramos que el $15 \%$ de la población de aquel curato entraba en la categoría de dependiente - esclavo, criado o agregado - y que un $20 \%$ de las casas registradas se valía de sus servicios. Como en otros espacios, se sumaban en grupos familiares, predominando los jóvenes, lo que sugería el carácter temporario de su condición. Sin embargo, lo más interesante a los efectos del análisis que sigue, es que solamente un tercio de los dependientes eran albergados en casas lideradas por jefes de familia destacados como «dones» y «doñas» único signo de distinción social que proporciona el censo- y más bien, la recepción de dependientes se vinculaba con el ciclo de vida de los hogares. Por otro lado, la relación de masculinidad era aún más baja para los agregados que para la población en general, revelando quizás mecanismos de solidaridad campesina y no solamente lazos verticales de subordinación.

A nuestro entender, los pleitos revelan nuevas dimensiones de la agregaduría, además de situaciones fronterizas con aquella condición ya que, como se verá a continuación, un antiguo propietario, un simple ocupante beneficiario de la «generosidad» de un dueño podía devenir en agregado o, más raramen-

fiscales, aún más numerosos. Palomeque, 1992: 54. Por su parte, Alberto Tasso examinó la estructura agraria de las zonas de bañado en Salavina y Atamisqui a partir del censo de 1895 y sus datos son congruentes con lo expuesto hasta ahora: allí, donde la pequeña propiedad se encontraba más difundida (el promedio para Salavina era de 5 ha por unidad), los agregados abundaban. En cuatro secciones de Salavina los arrendatarios conformaban más de la mitad de los productores y en la sección Pircas del departamento de Atamisqui los agregados eran la abrumadora mayoría (158 vs 7 propietarios). Así y todo, el autor ha corroborado que «la presencia de agregados u ocupantes es más intensa en las zonas ganaderas, caracterizadas por propiedades más grandes y producción de tipo extensivo y más escasa en las zonas de agricultura intensiva, de predios menores, con mayor trabajo personal de los propietarios que en cierta medida pueden prescindir de la mano de obra asalariada». Tasso, 2007: 81. Cabe recordar que en 1895 la especialización agrícola ya no era dominante, como ocurría hasta 1823, fecha de desvío del río Dulce en las antiguas zonas de bañado.

42 Citando disposiciones de Juan Felipe Ibarra de 1848 - que obligaban a los propietarios a socorrer sus agregados y a responsabilizarse por su comportamiento- Palomeque advertía en su artículo de 1992 sobre el intercambio búsqueda de protección/entrega de una renta en trabajo que implicaba la agregaduría. Todo ello, en un contexto de dificultad para el acceso a tierras en las zonas regadas.

43 Farberman, 1996: 33-59. 
te, escapar a la dependencia. Por otro lado, a fines de la colonia, agregado y arrendatario parecen haber sido sinónimos y quizás sólo más tarde el arrendamiento pudo implicar una relación más impersonal. En todo caso, si algo es seguro es que el agregado trabajaba y se asentaba en tierras ajenas, como lo expresaba nuestra recordada Gregoria Días:

El que aian vivido de tpo inmemorial los Noriegas en el consabido terreno, ha sido por tolerancia y consideración y no por eso obtienen goce personal y real porque si con ese motivo se adquiere ese dro ¡no habría en toda esta jurisdicción donde nacen tantos agregados, quien no tuviese propias ${ }^{44}$ !

Para Gregoria, el gran error de sus mayores había sido el de prestarles tierras caritativamente a sus primos y rivales. Pero la tolerancia y los préstamos no creaban derechos y por eso - a ojos de Gregoria - la condición de sus parientes intrusos era equiparable a la de los numerosos agregados santiagueños. Más allá de su veracidad, la cita nos persuade acerca de la importancia de la agregaduría como relación social en la región, explicando su génesis a partir del quebrantamiento de un pacto antiguo entre propietarios y desposeídos. Y, en rigor, lo cierto es que normalmente venimos a saber de los agregados en ocasión de su lanzamiento.

Por otra parte, no sólo los Noriegas de la rama «intrusa» (siempre desde la perspectiva de Gregoria Días) habían sido «tolerados» por los Luna. Ya don Andrés Luna - hijo del fundador del condominio - le había permitido al capitán Gregorio Adauto de la Xara instalarse «en un retazo de tierras de las qe poseía y poseemos con justo título». Muchos años después de aquella decisión, los descendientes de don Andrés se lamentaban de haber «tolerado el empréstito» «como humildes hijos». Ahora Adauto de la Xara mostraba los dientes, declarando a quien lo escuchara sus pretensiones sobre los campos.

Otro ejemplo nos lo proporcionan los compartes de Atamisqui, descendientes del tronco Santillán. Según la querellante Petronila de Luna y Cárdenas, su vecino don Diego Martínez de Lezana residía en la estancia gracias al préstamo fundado «en razón del parentesco que tenemos»" ${ }^{45}$. Como en el caso anterior, la generosidad había sido traicionada y ahora Petronila no conseguía

... tener el menor logro en cosa alguna, porque si es sembrar que hago yo y mis hijos más es para la familia del dho; que antes de ponerse en sazón de lo sembra-

44 Noriega Jose Javier contra don Gregorio Díaz. Sobre mayor derecho a tierras en la banda del río, 1808, AHSDE, Tribunales, legajo 2, exp. 38, f. 18.

45 Luna y Cárdenas, Petronila. Pide no sea incluida en un litis promovido por un hermano, 1750, AHSDE, Tribunales, legajo 5, exp. 48. 
do me lo destruyen y acaban, si es por ganados, tengo la experiencia que habiendo metido más de trescientas cabezas de ganado, actual no hallaré ni diez cabezas por haber dha familia e hijos del citado dn Diego consumídolos, de forma señor que me veo atosigada... por la población que este tiene que, aunque por sí y su mujer no coopere en cosa alguna, sus hijos y familia, que son unos ociosos, jugadores, executan y cooperan en cuanto perjuicio puede haver.

Los parientes pobres pretendían ser dueños para conducir a la ruina a los propietarios legítimos, tal el relato de doña Petronila que otros tantos dueños habrían podido suscribir. Es frecuente que los litigios inicien invocando la traición de estas estructuras portantes de la economía moral campesina, pero también de los señores rurales. Así, mientras los Noriega resistían la subordinación y Gregorio Adausto de la Xara proclamaba sus derechos sobre tierras ajenas, don Diego Martínez de Lezana nada hacía por impedir los supuestos latrocinios de sus hijos. La desautorización y el desacato, el desafío a la autoridad paterna, hacían a la mala fama de los agregados y de los huéspedes indeseados.

Don Diego Martínez de Lezana - cuyos derechos como condueño en Atamisqui eran, en rigor, incuestionables - llegó a ser alcalde ordinario del cabildo de Santiago del Estero. Aunque su casa — por el desorden que allí reinaba - fuera comparable con la «toldería de Alaykin», don Diego Martínez de Lezana se hallaba muy lejos de ser un pobre agregado aunque su contrincante así lo estigmatizara. Aún más, él mismo tenía «en su arrimo» a unos cuantos agregados «mulatos e indios», a quienes los vecinos responsabilizaban por «cuantos hurtos allí suceden... y spre se presume de ellos... en cuanta falla hay en ganados, sementeras y aun entrega del perchel del dueño de la estancia». En opinión de su contrincante, la misma desidia que Martínez de Lezana demostraba hacia sus hijos se trasladaba al «gobierno» de sus incorregibles dependientes, rompiendo con el principio de la paternal autoridad del campo común.

Por supuesto que los propietarios suprimían en sus relatos lo concerniente a la contrapartida de tanta «caridad». Ya que, una vez habilitados, los agregados contribuían con su fuerza de trabajo en un acuerdo que bien podía ser más formal e incluir un arriendo en dinero o en especie. Recordemos cómo se expresaba la dicotomía propietario / agregado en nuestro primer ejemplo: los Días eran dueños por no haber «servido o dado algún obsequio o pensión anual a ninguno de los Gomez ni a ninguna otra persona por razón de agregados en tierras ajenas». ¿Existía acaso alguna línea sutil que separara a los «agregados» de los arrendatarios que pagaban «pensiones»?

En otras regiones, la agregaduría solía comportar un vínculo más informal que el arrendamiento, de entrega eventual de trabajos establecidos por la 
costumbre. Sin embargo, puede que en Santiago los tantos se confundieran y el «servir» y aportar «obsequio o pensión anual» remitiera en la colonia tardía a una misma figura de dependencia. Aunque los expedientes judiciales nos ofrecen numerosos ejemplos, los dos que siguen parecen particularmente persuasivos.

El primero nos traslada a Tío Alto, en la zona de bañados del río Dulce ${ }^{46}$. Hacia 1763, el párroco de Guañagasta José Benavídez reclamó al Cabildo santiagueño que se lo amparase en sus derechos sobre la estancia. Como evidentemente Benavídez no residía en Tío Alto, fue necesario reunir una sumaria de testigos para establecer el origen de la propiedad y fijar sus linderos exactos $\mathrm{y}$, aunque todos los declarantes coincidieron en que las tierras habían pertenecido al «difunto Heredia», bisabuelo de Benavídez, ninguno dejó de mencionar a un tal Salvador Sequeira residente "sobre el río, en un rincón» de la estancia. Sobre Sequeira corrían diferentes versiones: según un declarante, el primer propietario le había «soltado un solar sobre el río para qe viviese y se mantuviese en dho solar»; según otro, «dho rincón o paraje le pertenecía (a Sequeira) pr voces pero qe no sabe si tuvo papeles». Como fuera, el asunto se definió en favor del cura, que cuatro décadas más tarde le vendió Tío Alto a un tal Pedro Pablo Rodríguez.

La primera tarea que ocupó a Rodríguez fue la de lanzar a tres familias. ¿Se trataba de agregados? Más bien, parecería tratarse de simples ocupantes ya que no tenemos noticias de que Benavídez se estableciera en Tío Alto alguna vez. Lo significativo es que, de las tres familias que se procuraba lanzar, una tuviera a un Sequeira como jefe y que éste se encontrara entre los más «contumaces» (por su resistencia a marcharse) habitantes de Tío Alto. ¿Sería Juan Sequeira el hijo o el nieto de Salvador? Es más que probable y no resulta osado hipotetizar que el hombre se tuviera por heredero de los derechos que su antepasado proclamaba para sí y que no había conseguido legitimar con papeles.

Dos años pasaron después de la compra y Rodríguez seguía reclamando al cabildo que se expulsara a los «agregados» — ahora sí aparece el término«principalmente la familia de Juan Sequeira, que hasta ahora y desobedeciendo los preceptos de la Real Justicia se hallan residenciando en las contenidas tierras, manteniéndose en ellas con resistencia». Fue así que una comisión designada por el cabildo se allegó hasta la estancia y conminó a los «agregados» de Tío Alto a pagar «el arriendo que adeudaran» a partir de la primera

46 Benavidez, José Gaspar sobre tasación y mensura, 1767, AHSDE, Tribunales, legajo 10, exp. 27. 
notificación recibida. En este acto, los «agregados» devinieron arrendatarios, quizás porque Rodríguez los necesitaba, quizás porque lanzarlos resultara complicadísimo, por no decir imposible. En todo caso, el propietario «quedó en paz» y los agregados / arrendatarios le prometieron «el debido decoro como a único señor de este terreno» y el saldo de las deudas pendientes. Sólo Juan Sequeira, ausente en aquel momento, parece haber quedado fuera del trato, mientras que su hija abandonó temporariamente su rancho y su anciana esposa «protestó toda subordinación en lo futuro» al nuevo dueño.

Sin embargo, tan trabajoso arreglo requeriría de ulteriores ajustes y ello tendría lugar en ocasión de una nueva transferencia de la propiedad. En 1800, Rodríguez le vendía Tío Alto a un potente vecino santiagueño, don Domingo Bravo de Zamora quien, junto con las tierras, recibía a los agregados/arrendatarios, incluyendo a Juan Sequeira y a las mujeres de su familia, «principales motoras» de la resistencia. Esta vez, su «enemigo capital» — como el nuevo propietario calificó a Juan Sequeira - contaba con el aval del cura Yacuriaga que, con una carta firmada de su puño y letra, habilitaba al agregado a sembrar y labrar tierras en Tío Alto. Así pues, además de tener que lidiar con un viejo agregado dispuesto a «levantar armas», Bravo de Zamora tenía que vérselas con un sacerdote que invitaba a su adversario a introducirse en su estancia «aunque fuera a fuego y sangre». La carta de Yacuriaga no consta en el expediente pero cabe preguntarse si no fue aquel el documento que Sequeira (infructuosamente) entregó a las autoridades capitulares para demostrar «el arraigo de su posesión» y sus derechos como labrador en Tío Alto $^{47}$. En cualquier caso, la decisión del cabildo fue la de concederle al rebelde agregado ocho días para marcharse de una vez por todas, permitiéndole cosechar el trigo que tenía sembrador con la ayuda de un peón ${ }^{48}$.

En el siguiente ejemplo, también del área de bañados, la transición de «intruso» a «arrendatario» parece haber sido más pacífica ${ }^{49}$. También aquí un propietario no residente, luego de validar sus derechos sobre la estancia de Sologo (Salavina), se propuso el lanzamiento de las familias «nocivas y perjudiciales» que «sin consentimiento del dho mi referido padre se han introdu-

${ }^{47}$ En efecto, se habla de la «carta qe públicamente presentó el dho Sequeyra, la que se apunta en autos practicados» para notificar más adelante sobre la devolución de «los documentos que ha presentado pa qe use de ellos cuando justifique con legitimidad su dro, respecto a que por ellos nada comprueba su pertenencia», AHSDE, Tribunales, legajo 10, exp. 27, f. 17.

48 Al parecer, la familia Sequeira contaba con una buena cantidad de bienes en Sologo. Se habla de una sementera de trigo y una de maíz, de caballadas y de una «majada crecida de ovejas» que «pacentaban» la madre y las hermanas de Juan Sequeira, AHSDE, Tribunales, legajo 10, exp. 27, f. 18.

49 Palavecino, Juan Vicente. Sobre mensura, 1775, AHSDE, Tribunales, legajo 10, exp. 20. 
cido». Así fue que, desde el inicio, se diferenció a los «intrusos»—que debían ser despojados sin mayores miramientos - de «los demás» ocupantes, intimados a reconocer y pagar arrendamiento. En el expediente constan seis «diligencias de despojo» - que otorgaban a los labradores un mes de tiempo para recoger la cosecha y abandonar la estancia- y tres «diligencias de arrendamiento» que quizás no fueran sino renegociaciones de pactos anteriores ${ }^{50}$. Significativamente, uno de los despojados prometió mudarse en lo inmediato al cercano «paraje del Simbolar, donde tenía sus chacras», como si las tierras de Sologo hubieran sido simplemente un complemento las propias.

¿Qué inferir de estos ejemplos? Lo primero es el carácter personal de la agregaduría o el arriendo. Mientras los dueños de Tío Alto o Sologo estuvieron ausentes, los ocupantes sin títulos no fueron molestados ya que no eran agregados a la tierra sino a un sujeto. Sólo en presencia de propietarios efectivos, los agregados devinieron en «intrusos» con los cuales cabían dos opciones: la expulsión o la negociación. El lanzamiento - a pesar de la violencia que implicaba - no parece haber sido tarea sencilla y podemos imaginar que el arriendo pudo representar en muchos casos un hacer las cuentas con la realidad del poder de la costumbre. De hecho, los precios comprometidos por los flamantes arrendatarios - de tres a cinco pesos anuales - parecen haber valido sobre todo como símbolo de la obediencia y subordinación hacia el dueño más que como un ingreso relevante. Por lo tanto, la deuda parece haber fundado la relación, deuda económica y sobre todo deuda moral (la deferencia debida al dueño, espejo del vínculo filial).

\section{EPÍLOGO}

Rosa Congost ha invitado a los historiadores a concebir los derechos de propiedad como construcción social, como producto histórico que refleja relaciones sociales entre individuos en torno a las cosas y no entre ellos y las $\operatorname{cosas}^{51}$. Un enfoque de esta naturaleza — que supone el carácter plural y mutante de los derechos de propiedad - debe atender a las prácticas, usos y costumbres, más allá de las normativas que los negaban o invisibilizaban. Aunque todavía nos

50 En un caso, la propuesta de arrendamiento parece provenir del intimado a desalojar las tierras. En efecto, a la orden del pedáneo, Josep Zerda solicitó que «si se le permitía, pagaría un arrendamiento de tres pesos en efectos de la tierra». En los otros dos casos, la oferta proviene del propietario. A Simón Zurita se le cobrarían «en cada un año cinco pesos en trigo mais u otros efectos de la tierra», AHSDE, Tribunales, legajo 10, exp. 20, f. 3.

51 Congost, 2007: 121-157. 
encontremos en una etapa preliminar, inspirados en estas recomendaciones, esperamos haber demostrado a través de ejemplos la relevancia de la mancomunión en la historia agraria y social santiagueña colonial y del siglo XIX. No obstante su existencia siempre precaria y amenazada, hipotetizamos que los campos comunes - situados en una región agraria central del Dulce- implicaban mucho más que una forma de poseer. Presente en las grandes estancias pero también (¿quizás sobre todo?) en las unidades campesinas, la mancomunión pudo representar también una modalidad peculiar de gestión de los recursos, de división del trabajo, de construcción de las jerarquías sociales y de organización de las relaciones comunitarias, incluso más allá de los umbrales del parentesco.

Como se anticipó en la introducción, es llamativo que la historiografía santiagueña (así como los textos folclóricos y las memorias descriptivas) no se haya ocupado de los condominios coloniales y decimonónicos, toda vez que su rastro en la toponimia y en el archivo judicial es tan abundante. Quizás el fenómeno pasó desapercibido por entrar en el terreno de las prácticas antes que en el de las leyes, por estar naturalizado en el paisaje y las costumbres, por emerger como problema casi exclusivamente a la hora del conflicto. Quizás porque la estancia - en Santiago como en la región pampeana - fue tradicionalmente asociada a la gran propiedad y el estanciero al gran patrón. Sin embargo, entendemos que la virtual negación de estas prácticas como problema histórico arraiga sobre todo en una tradición que sobrevaloró el pasado colonial de la región —y en particular las estancias «clásicas»— congelándolo en una imagen estereotipada.

La descripción de la estancia colonial santiagueña — no está claro de qué zona- que Orestes Di Lullo dejó en varios de sus textos cristalizó en nociones sólo parcialmente criticadas a posteriori. Dice Di Lullo en El bosque sin leyenda:

En torno de la «sala» patriarcal, el pueblo de los agregados semejaba la colmena ordenada y juiciosa. Era la estancia el centro de la sociedad y de la economía coloniales. (...) De ella salieron los pastores de los inmensos rebaños que poblaron los campos, los agricultores que roturaron la tierra, los primeros planteles de la artesanía y salieron también los milicianos de la libertad, los gauchos de las gestas civiles, los que, después de defender la patria contra la indiada, la organizaron definitivamente (...). Esta estancia, que constituye el principio de una sociedad ordenada y tranquila, donde no se conoce el salario $/ 63 / \ldots$ donde el patrón no explota y no castiga y el agregado es tan libre como el patrón, esta estancia que es un vasto taller, donde se elabora, en pacientes y alegres jornadas, lo indispensable para la vida sencilla es también la que cristaliza poco a poco la conciencia de la emancipación nacional ${ }^{52}$.

52 Di Lullo, 1999: 63-64. 
Es probable que esta edulcorada perspectiva, propia del revisionismo católico al que adscribía, no fuera compartida por muchos de sus contemporáneos y por los analistas que le sucedieron. Bernardo Canal Feijoo, por ejemplo, deploró las nostalgias por aquel pasado colonial fosilizado e idealizado, en el que primaba el orden (y no la anomia introducida por el fracaso de la modernización). No obstante, sí gozaron de consenso las nociones de la estancia como centro de la sociedad colonial, del predominio de relaciones no asalariadas en el campo, del difundido paternalismo de políticas caudillistas de Ibarra y los Taboada.

No todos los componentes de estas imágenes son falsos pero sí impresionistas y simplificadores, desconocedores de la vida y la densidad que rezuman los expedientes de archivo. Si en verdad los campos comunes ocuparon el corazón de la geografía de los bañados del Dulce y de la zona situada al norte de la ciudad, muchos problemas de la historia santiagueña — sobre todo los relativos a la política del siglo XIX, tan poco conocida- merecerían un cierto replanteo. Ya que, como esperamos haber demostrado, las relaciones horizontales eran tan importantes como las verticales, los agregados no tan obedientes y las jerarquías se discutían, incluso en el seno de las familias. El patriarcado no parece tan invencible, al fin y al cabo: ante nuestros ojos han desfilado mujeres a la cabeza de los campos comunes, que disponían de rebaños propios y que hasta resistían los desalojos, como la señora Sequeira. En suma, según nos parece, en aquellas «colmenas ruidosas» del río Dulce las relaciones sociales no se reducían al patronazgo y hasta para la agregaduría nos permitimos matizarlas. Entre armonías y conflictos, se desplegaba un complejo sistema de gestión y organización de la unidad campesina que incluía a la migración - a la que el campo común proveía de un contexto favorable - como una de sus estrategias posibles.

\section{BIBLIOGRAFÍA}

Boixadós, Roxana, «Transmisión de bienes en familias de elite: los mayorazgos en La Rioja colonial», Andes. Antropología e Historia, 10 (Salta, 1999): 51-78.

Boixadós Roxana y Farberman, Judith, «Propietarios, agregados y 'Pobres de Jesucristo'. Tierra y sociedad en Los Llanos riojanos en el siglo XVIII», Historia Agraria, 54 (Murcia 2011): 41-70.

Boixadós, Roxana y Farberman, Judith, «Mayorazgos, pueblos de indios y campos comuneros: la propiedad indivisa en La Rioja, siglos XVII a XIX», Revista de Ciencias Sociales, 7 (Bernal, 2015):19-46. 
Clavero, Bartolomé, «El común y no su doble. (A propósito de Pasado y Presente de los comunales y de lo comunitario», Quaderni Fiorentini per la storia del pensiero giruidico moderno, 31/II (Firenze, 2002): 899-915.

Congost, Rosa, «Sagrada propiedad imperfecta. Otra visión de la revolución liberal», Rosa Congost, Tierras, leyes, historia. Estudios sobre la "gran obra de la propiedad», Barcelona, Crítica, 2007: 121-157.

Consejo Federal de Inversiones, Estudio sobre las mercedes de Los Llanos, Buenos Aires, Mimeo, 1964.

De la Fuente, Ariel, Los hijos de Facundo. Caudillos y montoneras en la provincia de La Rioja durante el proceso de formación del estado Nacional Argentino (18571870), Buenos Aires, Prometeo, 2007.

Denis, Pierre, La valorización del país. La república argentina en 1920, Buenos Aires, Solar Hachette, 1987.

Di Lullo, Orestes, El folklore de Santiago del Estero. Material para su estudio y ensayos de interpretación) fiestas, costumbres, danzas, cantos, leyendas cuentos, fábulas, casos, supersticiones, juegos infantiles, adivinanzas, dichos y refranes, loros y cotorras, conocimientos populares, Tucumán, Universidad Nacional de Tucumán, 1943.

Di Lullo, Orestes, El bosque sin leyenda, Santiago del Estero, Universidad Católica, 1999.

Doro, Ricardo, Diagnóstico expeditivo de la situación jurídica, económica y social de las áreas en situación de comunidades indivisas de la provincia de Tucumán, Buenos Aires, Consejo Federal de Inversiones, 1974.

Fandos, Cecilia, «Estructura y transferencia de la propiedad comunal de Colalao y Tolombón (provincia de Tucumán) en la segunda mitad del siglo XIX», Mundo Agrario, 7/14 (La Plata, 2007), http://www.scielo.org.ar/scielo.php?script=sci arttext\&pid $=$ S1515-59942007000100012\&lng=es\&tlng=es.

Farberman, Judith, «Familia, ciclo de vida y economía doméstica. El caso de Salavina, Santiago del Estero, en 1819», Boletín del Instituto Ravignani, 12 (Buenos Aires, 1996): 33-59.

Farberman, Judith, «El "país indiviso". Derechos de propiedad y relaciones sociales en Los Llanos de La Rioja, siglos XVIII y XIX», Anuario de Estudios Americanos, 70/2 (Sevilla, 2013): 607-640.

Fazio, Lorenzo, Memoria histórica y descriptiva de la provincia de Santiago del Estero, Buenos Aires, Compañía Sudamericana de Billetes de Banco, 1889.

Grossi, Paolo, An Alternative to Private Property. Collective Property in the Juridical Consciousness of the Nineteenth Century, Chicago, The University of Chicago Press, 1981. 
Grossi, Paolo, “Assolutismogiuridico e proprietàcollettive", Quaderni Fiorentini per la storia del pensiero giuridico moderno, XIX (Firenze, 1990): 505-556.

Grossi, Paolo, La propiedad y las propiedades: un análisis histórico, Madrid, Civitas, 1992.

Larrouy, Antonio, Documentos del Archivo de Indias para la historia del Tucumán, Tucumán, Rosso, 1923, tomo II.

López, Cristina, «Tierras comunales, tierras fiscales. El tránsito del orden colonial a la revolución», Revista Andina, 43 (Lima, 2006): 215-238.

López, Cristina, «Derechos de propiedad en el Tucumán colonial. Fragmentación e indivisión de las tierras rurales», Bibliographica Americana, 11 (Buenos Aires, 2015): 80-100.

López, Cristina y Bascary, Ana María, «Pueblos de indios de Colalao y Tolombón: identidad colectiva y articulación étnica y social (siglos XVII-XIX)», Humanitas, XXVII (Tucumán, 1998): 71-112.

Olivera, Gabriela, Por travesías y oasis. Mercados, producción agraria y actores sociales de La Rioja (Los Llanos y Arauco, 1900-1960), Córdoba, Universidad Nacional de Córdoba, 2000.

Palomeque, Silvia, «Los esteros de Santiago. Acceso a los recursos y participación mercantil: Santiago del Estero en la primera mitad del siglo XIX», Data, 2 (La Paz, 1992): 9-61.

Rossi, María Cecilia y Banzato, Guillermo, «Explorar y medir en tierras de caudillos. Amadeo Jacques en Santiago del Estero, 1856-1858», Juan Carlos Garavaglia y Pierre Gautreau (eds.), Mensurar la tierra, controlar el territorio. América Latina, siglos XVIII-XIX, Rosario, Prohistoria, 2011: 215-258.

Rossi, María Cecilia y Rízolo Burgos, Juan Víctor, «Las leyes sobre tierras públicas en Santiago del Estero. 1858-1862», Guillermo Banzato y Graciela Blanco, La cuestión de la tierra pública en Argentina: a 90 años de la obra de Miguel Ángel Cárcano, Rosario, Prohistoria Ediciones, 2009: 133-162.

Tasso, Alberto, «Reproducción secular de la pobreza rural. Dimensiones sociohistóricas de un caso de exclusión estructural», Realidad Económica, 47 (Buenos Aires, 1997): 46-62.

Tell, Sonia, «Expansión urbana sobre tierras indígenas. El pueblo de La Toma en la Real Audiencia de Buenos Aires», Mundo Agrario, 10/2 (La Plata, 2010). Recuperada en http://www.memoria.fahce.unlp.edu.ar/art_revistas/pr.4174/pr.4174.pdf.

Tell, Sonia, «Títulos y derechos coloniales a la tierra en los pueblos de indios de Córdoba. Una aproximación desde el siglo XIX», Bibliographica Americana. Revista interdisciplinaria de estudios coloniales, 7 (Buenos Aires, 2011): 201-221. 
Tell, Sonia, «Campos en común, campos contendidos. Apropiaciones de la comunidad en Córdoba (siglo XIX)», Revista de Ciencias Sociales, 27 (Bernal, 2015): 67-85.

Vassberg, David, La venta de tierras baldias. El comunitarismo agrario y la corona de Castilla durante el siglo XVI, Madrid, Servicio de publicaciones agrarias, 1983.

Vessuri, Hebe, La expansión agrícola de la década del ochenta. El caso de una región mediterránea, informe técnico, San Miguel de Tucumán, Centro de Investigaciones Sociales, Universidad Nacional del Tucumán, 1972a.

Vessuri, Hebe, «Tenencia de la tierra y estructura ocupacional en Santiago del Estero», Desarrollo Económico, 12/46 (Buenos Aires, 1972b): 351-385.

Zubrzycki, Bernarda, «Campos comuneros en el valle de Hualfín (Catamarca). Antecedentes, problemática y situación actual», Andes, 13 (Salta, 2002): 1-13.

Zubrzycki, Bernarda, «Herederos, dueños y "derechosos". Propiedad y herencia de la tierra en Asampay, Argentina», Sociedades rurales, producción y medio ambiente, 4/1 (Xochimilco, 2003): 19-27.

Fecha de recepción: 28 de abril de 2016.

Fecha de envío de las modificaciones: 5 de octubre de 2016.

Fecha de aceptación: 12 de octubre de 2016.

\section{The vicissitudes of Mancomunión. Undivided property, harmony and conflict in the Rio Dulce region. Santiago del Estero (Argentina), eighteenth and nineteenth centuries}

In the province of Santiago del Estero, in north-west Argentina, mancomún meant collectively-managed undivided properties. This type of communal agrarian structure was widely found throughout the region in colonial times and in the nineteenth century; it could be found both in large estancias and small peasant properties alike. Based on colonial examples in the Rio Dulce region, this article focuses on three issues pertaining to undivided properties: rationality, membership and internal hierarchy.

KeY WORDS: Property rights; mancomún; Santiago del Estero; colonial period; undivided property. 